\title{
Actualidad y necesidad del pensamiento crítico: ¿Demasiados hombres u hombres sobrantes?
}

\author{
Georges Labica \\ Traducción: Edgardo Logiudice \\ Revisión técnica: Ana G. Logiudice
}

Queridos amigos:

Para respetar el tiempo convenido, me limitaré a hacer algunas proposiciones, evidentemente puestas en discusión.

Sin embargo, ante todo, dos palabras sobre el debate que pone el acento en los conflictos entre las civilizaciones, ya que esto puede ser considerado como cuestión previa. Me parece importante precisar que esos conflictos, llamados de civilización, son el producto de contradicciones internas a cada conjunto, contradicciones sociales, económicas y políticas, a menudo descuidadas u ocultadas, cuando se habla de diferencias y enfrentamientos culturales o religiosos. Por otro lado, el peligro que nos ocupa hoy no es el de un conflicto, sino de la dominación de una civilización sobre todas las otras: la de la potencia que domina el mundo económica y militarmente. La desgracia es que esta civilización presenta la particularidad de ser una no-civilización, cuyo valor fundamental se reduce a la ganancia (co al lucro?) y a la maximización del beneficio - lo que algunos designan con el término de macdonalización-. Por lo tanto, hay que temer que una tal 
monocivilización, y el "pensamiento único" que la acompaña, lleguen a ser portadores de la barbarie. La World culture, es decir, la supuesta cultura de masas, de hecho bajo el estricto control del marketing y la industria del esparcimiento, no es más que una cultura náufraga (Ignacio Ramonet). Recíprocamente, es necesario reconocer que, a pesar de la calidad de los análisis producidos desde hace tiempo por los mismos marxistas, no está hecha toda la luz sobre el desmoronamiento de los países del "socialismo realmente existente". En particular, tratándose de la conjunción y del rol recíproco de los factores internos (descomposición avanzada, estagnación, incapacidad de entrar en el desarrollo económico moderno, etc.) y de los factores externos (rol del imperialismo y de la Iglesia, desapego del Tercer Mundo y las clases obreras de Occidente), de los cuales el gorbachovismo ha sido un reflejo, a la vez deformado y singularmente unilateral, pero esto es otra historia.

El segundo punto, sobre el que seré un poco más explícito, concierne a la mundialización o globalización, como se quiera decir. Notemos, de entrada, que ella es inherente al capitalismo desde su aparición. Es su tendencia natural la que conduce a la conquista del planeta a través del aplastamiento de los otros modos de producción. Durante un largo período, esta vocación de dominación podía encontrar resistencias de parte de las naciones, de conjuntos culturales, o de otras relaciones de producción, aunque esos combates estuvieran perdidos de antemano. Este ya no es más el caso: esas posibilidades están, o muy reducidas, o son inexistentes, o están profundamente cambiadas. Más adelante, me referiré a ello. La mundialización es, como se sabe, el reino del capital financiero, pero ese fenómeno es transcultural, transnacional. Las verdaderas potencias que gobiernan el mundo no son más los Estados-naciones, que si no están en vías de extinción, al menos su influencia se encuentra sumamente disminuida: repartidos, como están, los imperativos neoliberales del mercado internacional y la siempre necesaria vigilancia de sus grupos sociales agredidos por estos imperativos, mejor dicho, por las multinacionales, cuyo nombre dice bien lo que quiere decir, ya que son, a la vez, supra y transnacionales. Agreguemos a ello que, en el seno de la mundialización, son las capas más duras, es decir, la parte más intransigente de la burguesía, que ejercen solas el control, cu+1 $\ldots$, hace poco tiempo, la dominación suponía compromisos entre las diterentes fracciones que 
la componían, y maridajes con las clases medias. No hay más delicadezas, así lo constatan en Europa Occidental, muchos sociólogos y politólogos. Las capas medias no se benefician de ninguna protección; con mayor razón, los trabajadores. Este asunto es nuevo. Aquí se marca la agravación de las desigualdades para con los más desprotegidos y su extensión a los nuevos actores, bajo la forma, por ejemplo, de las incertidumbres sobre la reproducción social de generaciones enteras. Me limito a mencionar, en el plano internacional, los ataques del sistema contra toda forma de desarrollo que tienda a sustraerse a sus directivas, y que comprende entre ellos a los países "emergentes" como Ruanda, en que la organización agrícola es saqueada, o, sin duda, Yugoslavia. La llamada mundialización se cultiva con resguardos ideológicos, no solamente de parte de representantes consagrados de cualquier administración, como un Fukuyama o un Huntington, sino también de parte de personajes que detentan palancas de mando. Ustedes conocen a Michel Camdessus, el Director General del FMI. Michel Camdessus es católico, lo cual, por supuesto, es su derecho. Ahora bien, en una conferencia ofrecida en Lille, hace algunos años, ante un congreso de hombres de negocios cristianos - que ha sido analizado por uno de nuestros amigos, Franz J. Hinkelammert, de Costa Rica, M. Camdessus, a fin de dar un alma, como señala Hinkelammert, a los reajustes estructurales — dicho de otro modo: de servir a "la teología del Imperio" - se empeña en mostrar que la "opción por los pobres" (la de Cristo) no fue otra que "la opción por el FMI", que mercado y solidaridad fueron sinónimos, que el mercado era "el Reino" y que "la política del FMl ha sido transformada en voluntad de Dios sobre la Tierra", quedando entendido que se necesita encuadrar la lógica del mercado, a fin de evitar los efectos negativos. De donde toda perspectiva de alternativa es excluida: iello va contra la voluntad de Dios! Y, como lo nota aún Hinkelammert, Estado de Derecho y totalitarismo, democracia y totalitarismo, resultan conciliables. Pienso también en las recientes declaraciones de una personalidad conocida por todos y que no se podría suponer de izquierda, Georges Soros, que ha amasado una considerable fortuna con la especulación y ejerce un generoso mecenazgo a favor de los países del Este europeo, del que es originario - nació en Hungría-. El señor Soros ha publicado, el 15 de enero pasado, en el principal diario sueco, un artículo (luego retomado en un libro, La crisis del capitalismo mundial, París, Plon, 1998) cuyo titular se desplegaba en toda la portada: "El liberalismo es 
el peor peligro para la democracia", donde asegura que, para él -que está idealmente ubicado para ver las cosas desde dentro- ese peligro es peor que el que se corrió con el comunismo o el socialismo realmente existentes. Tomar nota. Por otro lado, es muy significativo constatar que, hace algunos meses, la prensa francesa vuelve de su discurso triunfalista del día siguiente a la caída del muro de Berlín. Un semanario titula: “iFuego sobre el capitalismo!”. iOtros muchos anuncian "El retorno de Marx"!

Hay otro punto que quiero señalar hoy. Se trata de un fenómeno poco percibido, porque está disimulado bajo los discursos ideológicos. Hablaré de lo que Marx puso en evidencia cuando mostró que el proceso de trabajo del capitalismo producía, en su época, bajo el impacto del maquinismo, con el desempleo, un "ejército industrial de reserva". Utilizaba fórmulas tales como "población obrera excedente", trabajo "vuelto superfluo", "creación de una superpoblación relativa", etc., y la más lacónica aún: "hay demasiados hombres". Las relaciones capitalistas de producción, llegadas al estadio de la globalización, dan a estos juicios su extensión más considerable y, a la vez, la más dramática: hay demasiados hombres. He aquí la verdad. El vocabulario se ha vuelto corriente, particularmente la prensa no deja de acercarse a esa constatación, pero se niega a llegar a ella y a denunciarla. Escuchemos lo que dicen las palabras, que jamás son inocentes. Por ejemplo, los términos de "marginalidad", "marginados", palabras poco usuales y, sin embargo, literalmente banalizadas. En literatura, el margen no existe jamás sin el texto, del que es su blanco, su afuera. La metáfora es clara: el margen está devorando al texto, se come la página. Más terrible aun y, sin embargo, también vulgarizado, neutralizado, es el término exclusión. El lenguaje político periodístico, impermeable a toda indignación, nos fatiga las orejas con los "excluidos". Pero, ¿qué quiere decir "estar excluido", sino descartado, puesto al margen? Y no solamente de la vida económica, sino también de la vida social, cívica, cultural y, a menudo, sexual —en el sentido en que se habla de "miseria sexual"tratándose en particular de los trabajadores inmigrantes. Cuando los individuos venden sus propios órganos a los laboratorios, se entregan a un verdadero tráfico de carne humana, a fin de sobrevivir simplemente, ¿es excesivo hablar de exclusión de la existencia misma? Por otra parte, ćacaso no sabemos que esta expulsión funciona dentro del sistema, que es su producto directo, estructural, y no accidental? La 
exclusión está, en realidad, incluida, y el sistema lo sabe tan bien que gasta algo en la buena conciencia de las intervenciones humanitarias y caritativas frente a los que ha proscrito, al punto que Michel Chossudowski ha podido hablar de "simbiosis entre intervenciones de carácter militar, o humanitaria, o geopolítica, y las preocupaciones económicas, macroeconómicas de las instituciones internacionales". Los bomberos de la asistencia son los pirómanos de la agresión. La subhumanidad de la marginalidad y de la exclusión no provienen más que de la naturaleza, como en los viejos tiempos, ellas surgen directamente del desarrollo y del libre mercado. Decía que la exclusión se extiende a todas las formas de la vida social, de la cual, en lo político, agregaría, entre los no excluidos stricto sensu, la exclusión hace también sus estragos bajo la forma de la autoexclusión, del abstencionismo electoral, que hacer renunciar a los ciudadanos de su primer derecho: el de dar opinión sobre los asuntos comunes. En lo sucesivo, tal es la tendencia más acusada de las democracias que se pretenden "modelos": individuos cada vez más numerosos desertando de las urnas. Así, el jefe de la mayor potencia del mundo, los Ee.UU., representa solamente un poco más del tercio del electorado del país y, como de costumbre, este ejemplo hace escuela en las naciones europeas. Los ciudadanos hacen saber claramente que no encuentran en los políticos, hombres o ideas, ofertas a sus sufragios, sostenes adecuados a sus necesidades y a sus voluntades. Que no se pretenda que tal actitud proviene de la dimisión a la ausencia de espíritu cívico Es una expresión político marginalizada, también, seguramente, pero determinada, de la contestación, sino del rechazo, de las consecuencias de la mundialización en curso.

¿Qué son esos "hombres de más"? Los desocupados, sin duda, salvo precisar que ellos no son más asimilables, precisamente, a un "ejército de reserva", a la que se podría apelar en caso de necesidad por el mercado de trabajo, ya que el sistema ha dado la prueba de que el paro y el desempleo no tiene nada de provisorio, que permanecen dentro de lo inevitable, de lo definitivo, a pesar de los discursos tranquilizantes del retorno del crecimiento. Esta situación golpea a gente cada vez más joven, así lo atestiguan todas las estadísticas. He aquí los supernumerarios, de los que se puede, o debe, prescindir. Ustedes saben, como yo, hasta qué punto puede ser dolorosa la conciencia que toman los individuos, de sus destinos de seres inútiles, derrotados o 
marginados, sin porvenir. Los inmigrantes constituyen otra categoría. Actualmente, se ven bien en Francia con la adopción de leyes y reglamentos que tienen un carácter discriminatorio, racial y, a veces, abiertamente racista. El mismo vocabulario banalizado encierra la distinción entre extranjeros e inmigrados. A los primeros, la mirada tolerante; a los segundos, la amenaza de expulsión reservada para los que están de más. Los extranjeros, sobre todo, si provienen de la comunidad europea, no pueden ya ser inmigrantes; el inmigrante, sobre todo si es originario del Magreb o del África negra, si es moreno, o de "tipo árabe", no podría ser considerado como extranjero. A menos que petróleo y dólares autoricen las excepciones y modifiquen los criterios. Así, a pesar de las apariencias, un jeque de Kuwait merece la calidad de extranjero y puede habitar en el $X V I^{\text {eme }}$ arrondisement. Esto es una manera, para un país como Francia, de destruir su documento de identidad, heredado de la Revolución. Existen, finalmente, todas las diferencias, cuya afirmación, cada vez más fuerte, impone su corolario a las identidades. Ese par diferencia-identidad, por supuesto, funciona para la exclusión, para los "hombres de más". La insistente referencia contemporánea a las "comunidades" no tiene otro sentido, sean éstas étnicas, religiosas, culturales o sexuales: tienen la vocación de producir supernumerarios. Existe un caso en el mundo, que ustedes conocen bien, que atestigua la presencia de una verdadera población de hombres de más, esta vez a escala internacional: la población de los palestinos, que no son otros, como se ha dicho justamente, que "los indios de los israelíes". Los individuos, despojados de su dignidad humana, desposeídos de sus derechos, están a merced de un Estado que se nos presenta, también él, como una democracia, de modelo de crecimiento para sus vecinos, y que acaba de hacer figurar la tortura en su Constitución. El asunto es propiamente inaudito, ya que si, desgraciadamente, es verdad que la tortura existe en casi todos los países, nadie, hasta aquí, había llegado al cinismo de legalizar su práctica.

Frente a tal situación, de la que no he podido más que sugerir algunos rasgos, ¿cuáles pueden ser las fuerzas de resistencia susceptibles de controvertir su curso? Digo curso, para subrayar que con la mundialización tenemos todavía un asunto en proceso, para nada arribado a su término, del que podemos demostrar con facilidad que tal aspecto se puede volver positivo: las complementariedades productivas, por ejemplo, o la conversión de la uniformidad en universalidad, 
o la planetarización de los derechos y de los medios de comunicación. Quizá no sea inútil volver atrás un instante sobre las formas de oposición demasiado simples, inadecuadas, o propiamente impotentes, cuya caricatura es aquella de los "brazos caídos", como se dice familiarmente, o "estás con los brazos cruzados", que significa que no hay nada que esperar, que la suerte está echada. Tenemos, en primer lugar, las políticas socialdemócratas o socialistas, que han fracasado claramente, en su voluntad de señalar los efectos más devastadores del neoliberalismo. Es suficiente mirar hacia Alemania, Italia, Francia o España: la mayor parte de las naciones europeas han conocido esas experiencias de reforma, tratando de controlar la flexibilidad aquí, de introducir una dosis "social" allá, o, como otros, de moderar las exigencias de los organismos transnacionales. Daría vergüenza citar a los países ex socialistas, en los que las conversaciones, tanto al neoliberalismo como a la socialdemocracia han engendrado las catástrofes que ya conocemos. Las desigualdades de todo orden no han cesado de crecer. Los provechos de productividad, creadores de riqueza, han aumentado la pobreza. La conquista de partes del mercado ha destruido sistemáticamente cada vez más empleos. Europa presentó como saludable el acabar su construcción con cerca de veinte millones de parados y con 57 millones de personas viviendo por debajo de la línea de pobreza (oficial), es decir, el 17\% (el 23\% para Gran Bretaña, paraíso del liberalismo). El posible retorno al poder de esas fuerzas, gracias al juego de alternancias gubernamentales que mistifican la opinión, no conlleva más que ilusiones: la "izquierda” sustituirá a la derecha en la gestión de relaciones capitalistas. En segundo lugar, se encuentran las proposiciones, que no son todavía políticas en acto, de la extrema derecha. Su audiencia creciente, medida por los resultados electorales, no tiene nada de sorprendente, ni, menos aún, de pasajero; proviene en línea directa, como su consecuencia, a la vez, de los desastres económicos, sociales y morales provocados por la mundialización y la defección de las izquierdas tradicionales. Sin duda, sus respuestas a la globalización no son solamente malas, sino peligrosas. Sin embargo, lo que importa es que son las respuestas adoptadas como tales, asumidas en la confusión y la ignorancia, por las masas más duramente golpeadas (el Frente Nacional, en Francia, se puede presentar como "el primer partido obrero"). En nuestra revista de lo que es necesario no hacer, un lugar, en verdad muy próximo a lo precedente, está reservado a los fundamentalismos y a otros integrismos, sean ellos de 
carácter étnico o religioso, y que éste último sea musulmán, judío o católico. No se trata aquí solamente de pronunciar condenas éticas, sino de convencerse de que tales actitudes no representan ningún peligro para el liberalismo. Lo que sabemos de sus programas económicos y políticos no es para nada incompatible, no obstante las fanfarronerías verbales, con la sumisión a las relaciones dominantes, no más que con la tutela estadounidense. Miremos de paso al Fis argelino, a Tourabi en Sudán, la Península Arábiga o los talibanes afganos. La administración de los E.E. UU. tiene ahí buenos y leales aliados. La ideología de los Derechos del Hombre, a su vez, ¿servirá de defensa? Seguramente todo el mundo está de acuerdo con los Derechos Humanos, su promoción y su defensa, pero la ideología es cosa diferente, lo que quiere decir que ciertas potencias se arrogan el monopolio de la definición y del respeto de los derechos humanos. Es así también cómo una disposición de la Unión Europea prevé ligar la ayuda económica a los países en desarrollo a las garantías de respeto de los derechos humanos. Es necesario recordar que los autoproclamados defensores de los derechos humanos son, precisamente, los que se liberan de escrúpulos cuando se trata de servir sus propios intereses, como puede verse, de manera brillante, en la ocasión de la Guerra del Golfo, las expediciones a Grenada, Panamá o Nicaragua, las intervenciones armadas al Cercano Oriente, en África, o aún en Vietnam (la lista no es exhaustiva). Mientras que el primer derecho, como lo afirmaba nuestro viejo maestro Hegel, es "el derecho a la existencia", trágica y deliberadamente despreciado por el liberalismo.

El último señalamiento que haré parecerá más positivo. Querría poner de relieve otro rasgo oculto de la mundialización: saber que, gracias a ella, no existe más que un solo enemigo. Hubo un tiempo, no muy lejano, donde las especificidades nacionales empañaban la percepción de los denominadores comunes: la Argentina no era Grecia, que, a su vez, no era Etiopía, ni Túnez. Hoy las cosas han cambiado: cualesquiera que sean sus diferencias, estos países, como otros, se encuentran ubicados bajo los mismos dictados del FMI, del Banco Mundial o, más recientemente, de la OMC (Singapur, 1996, que ya preparaba los AMI - Acuerdos Multilaterales sobre Inversiones-). No obstante los matices de las obligaciones, unos están "invitados" a ajustarse rápidamente a las condiciones requeridas por la moneda europea; los otros, a reembolsar su deuda, quedando bien entendido que la 
deuda es literalmente impagable, y que ello no tiene más objeto que arruinar a aquellos que recurren al endeudamiento. Un solo enemigo es el que designa la multiplicación de los recientes movimientos, como las huelgas de fines de 1995, en Francia, abiertamente orientadas contra la política liberal, o el rechazo de las Renault transformada en "euro-huelga", gracias menos a los sindicatos obreros que a la patronal, es necesario decirlo, y es evidente: todos los movimientos que se manifiestan en el mundo entero, bajo formas diversas, la revuelta contra el orden establecido, esas fuerzas - como decía Gramsci- que el capital no cesa de hacer elevar contra él: de Chiapas a Hebrón, de las Madres de Plaza de Mayo a los siderúrgicos de Seúl. Por tanto, no temo afirmar que es nuestro deber, en respuesta a las dimisiones y traiciones de toda especie, dar vida a aquellas palabras que los ideólogos al servicio de los dominantes han declarado, muy apresuradamente, caducas: la palabra imperialismo, la de clase, la de revolución, la de utopia, entre otras, todas exigidas por la necesaria radicalidad de la alternativa a construir.

Desearía personalmente, para concluir, excusarme de haber sido demasiado extenso y demasiado breve al mismo tiempo. Que esta conferencia, por la que felicito a los organizadores el haber tomado la iniciativa, nos permita a cada uno, desde lo que es y desde donde está, construir los fundamentos de un nuevo internacionalismo, a fin de hacer frente a los peligros extremos de la mundialización neoliberal. Les agradezco. 